\title{
TOWARD A Synthesis OF MODElS OF REgulatory POLICY DESIGN WITH LIMITED INFORMATION
}

\author{
MARK ARMSTRONG \\ University College London \\ Gower Street London WC1E 6BT \\ E-mail: mark.armstrong@ucl.ac.uk \\ DAVID E. M. SAPPINGTON \\ University of Florida \\ Department of Economics, P.O. Box 117140 \\ Gainesville, FL 32611-7140 \\ E-mail: sapping@ufl.edu
}

\begin{abstract}
We develop a simple, yet general, model that admits as special cases several key analyses of the design of regulatory policy in the presence of asymmetric information. In doing so, we help to identify the central differences and similarities among the diverse analyses in the literature.
\end{abstract}

Key words: regulation, asymmetric information.

JEL Classifications: D82, L51.

\section{Introduction}

The basic model of regulatory policy design in the presence of asymmetric information is quite simple. It examines the interaction between a regulator and a regulated (monopoly) firm in a setting where the firm is endowed with privileged knowledge of some relevant aspect of the regulatory environment (e.g., the firm's operating costs or consumer demand). Cognizant of this information asymmetry, the regulator designs policy rules that govern the (non-repeated) interaction between the two parties. 
Despite its simplicity, this basic regulatory problem admits a wide range of solutions with very different properties. For example, at the solution to the "standard" problem, the firm typically commands rent from its privileged information. To limit this rent, induced performance typically is reduced below the full-information level, except in the most favorable environment. ${ }^{1}$ In addition, the firm's induced performance generally varies with the realization of its private information.

Although these features of the solution to the standard regulatory problem are well known and well understood, they do not characterize the solution to all such regulatory problems. Seemingly minor variations in the details of the standard regulatory problem can give rise to solutions with very different qualitative features. For instance, the firm's induced performance may not vary as the environment changes, and the firm's performance may exceed full-information performance levels in some settings. In other settings, the regulator can induce the full-information performance levels without ceding any rent to the firm.

1. The full-information performance level is the level that would be induced in the absence of any information asymmetry. 
Although these findings are well documented in the literature, the literature does not provide a unified analysis of the wide range of regulatory problems with asymmetric information that have been analyzed. Nor does it offer a comprehensive explanation of the diverse findings that these models deliver. ${ }^{2}$ The present research is designed to fill a portion of this gap in the literature. We develop a simple, yet general, model that admits as special cases several canonical models of regulatory policy design in the presence of asymmetric information that have been explored in the literature. We then explain how this general model can be solved, and identify the features of the model that give rise to the different findings that have been derived in the literature. ${ }^{3}$

The analysis proceeds as follows. Section 2 describes the central elements of the simple, discrete regulatory policy design problem that we analyze. Section 3 reviews the varied solutions to this problem that have been presented in the literature. Section 4 develops a unified framework in which the varied findings in the literature are readily derived, analyzed, and compared. Section 5 presents

2. Guesnerie and Laffont (1984) provide a unified analysis of basic adverse selection problems in settings where an agent's (e.g., a firm's) private information is the realization of a continuous random variable. Caillaud et al. (1988) offer a corresponding unifying analysis that incorporates several extensions of the basic adverse selection problem, including repeated interactions, imperfect monitoring of the firm's private information, and imperfect performance observation. Laffont (1994) presents an extensive review of key regulatory problems with asymmetric information, including settings where firms bid for the right to serve as the monopoly supplier and settings where the regulator's intertemporal commitment powers are limited. We focus on static settings with full commitment where the firm's performance is observed perfectly and its private information cannot be monitored. Most importantly, we assume the firm's private information is the realization of a binary random variable. Although the features of the solutions to continuous and discrete adverse selection problems are qualitatively similar, the analytic techniques employed to solve the two types of problems differ significantly. Our analysis also incorporates several extensions of the basic adverse selection model that have been developed since the important early analyses of Guesnerie and Laffont (1984) and Caillaud et al. (1988) and that are not addressed in Laffont’s (1994) review.

3. Our purpose is not to defend or to advocate the models in the literature. (See Crew and Kleindorfer (1996) and Vogelsang (2002) for critiques of the literature.) Rather, we seek to identify common elements of seemingly disparate analyses in the literature and thereby to facilitate comprehension of the 
concluding observations. Any formal proofs not presented in the text are provided in the Appendix.

\section{Elements of the Model}

The central complication in the regulatory models under consideration is that the regulated firm acquires private information about the environment in which it operates before the regulator and firm begin their non-repeated interaction. The private information pertains either to the firm's operating costs or to consumer demand for the regulated product.

literature. 
We consider the setting in which the firm's privileged information is binary. ${ }^{4}$ The firm learns at the outset whether the state of the environment is "low" ( $L$ ) or "high" ( $H$ ). The ex ante probability of the low state is $\phi \in(0,1)$. The corresponding probability of the high state is $1-\phi$. The realized state of the environment affects the firm's profit. $\pi_{i}(p)$ will denote the firm's profit in state $i \in\{L, H\}$ when the firm charges unit price $p$ for its product. The equilibrium price in state $i$ is denoted $p_{i}$. The corresponding transfer payment from consumers to the regulated firm is $T_{i}$. The firm's opportunity profit level is normalized to zero, so the firm's rent ( $R$ ) is the sum of its profit and the transfer payment it receives. Formally, the firm's equilibrium rent in state $i$ is $R_{i}=\pi_{i}\left(p_{i}\right)+T_{i}$

Consumers derive net value $v_{i}(p)$ from the opportunity to purchase the regulated product at unit price $p .^{5}$ Equilibrium consumer surplus $(S)$ in state $i$, then, is $v_{i}\left(p_{i}\right)-T_{i}$. The regulator seeks to maximize a weighted average of expected consumer surplus and rent, where $\alpha \in[0,1)$ is

4. Jullien et al. (2003) provide a complementary analysis of binary agency models in which the agent is privately informed about his degree of risk aversion. The authors employ techniques similar to those presented in section 4 below.

5. $\quad v_{i}(\bullet)$ is a strictly decreasing, convex function. 
the weight applied to rent. ${ }^{6}$ This weighted average in state $i$ is:

$$
S_{i}+\alpha R_{i} \equiv v_{i}\left(p_{i}\right)-T_{i}+\alpha\left[\pi_{i}\left(p_{i}\right)+T_{i}\right] \text {. }
$$

6. To avoid uninteresting considerations, we focus throughout on the case in which the regulator induces strictly positive output from the firm in both states. This policy will constitute the optimal regulatory policy whenever the value of output to consumers sufficiently exceeds the firm's cost of producing output in both states. 
The reduced weight ( $\alpha<1$ ) on rent reflects a greater innate concern for the welfare of consumers. Letting $w_{i}(\bullet)$ denote the (unweighted) sum of consumer surplus and profit in state $i$ $\left(v_{i}(\bullet)+\pi_{i}(\bullet)\right),{ }^{7}$ the regulator's objective in equation (2.1) can be rewritten as:

$$
S_{i}+\alpha R_{i}=w_{i}\left(p_{i}\right)-[1-\alpha] R_{i} .
$$

The regulator's objective, then, is to maximize:

$$
W \equiv \phi\left[w_{L}\left(p_{L}\right)-[1-\alpha] R_{L}\right]+[1-\phi]\left[w_{H}\left(p_{H}\right)-[1-\alpha] R_{H}\right]
$$

To ensure that price $p_{i}$ and transfer payment $T_{i}$ are implemented in state $i$, the firm must prefer the $\left(p_{i}, T_{i}\right)$ option to the $\left(p_{j}, T_{j}\right)$ option in state $i$. Formally, the following incentive compatibility constraints must be satisfied:

$$
R_{i} \equiv \pi_{i}\left(p_{i}\right)+T_{i} \geq \pi_{i}\left(p_{j}\right)+T_{j} \quad \text { for } j_{-} i, \quad i, j \in\{L, H\} \text {,(24a) }
$$

or, equivalently:

$$
R_{i} \geq R_{j}+\pi_{i}\left(p_{j}\right)-\pi_{j}\left(p_{j}\right) \quad \text { for } j_{-} i, \quad i, j \in\{L, H\} \text {. (24b) }
$$

In addition, the firm must be assured of non-negative rent in both states, so the following participation constraints must be satisfied:

$$
R_{i} \geq 0 \quad \text { for } \quad i=L, H .
$$

The regulator's problem, then, is to choose the $\left(p_{L}, T_{L}\right)$ and ( $\left.p_{H}, T_{H}\right)$ options to maximize $W$ as defined in expression (2.3), subject to constraints (2.4) and (2.5). Call this problem $[P]$ for future reference.

7. $w_{i}(p)$ is assumed to be a single-peaked function of $p$, for $i=L, H$. 
If the regulator shared the firm's knowledge of the realized state, she would eliminate the firm's rent and set the regulated price at its full-information level, $p_{i}^{*}=\underset{p}{\operatorname{argmax}} w_{i}(p)$, which is the firm's equilibrium marginal cost of production in that state. This ideal outcome for the regulator will be referred to as the full-information outcome. The extent to which asymmetric information limits the regulator's ability to achieve the full-information outcome is reviewed in section $3 .{ }^{8}$

\section{Findings in the Literature}

Before characterizing the solution to $[P]$, consider briefly the three main variants of this problem that have been analyzed in the literature: (1) the setting with unknown variable costs; (2) the setting with unknown variable and fixed costs; and (3) the setting with unknown demand.

8. The regulator's preference for consumer surplus over profit ( $\alpha<1$ ) is the only cost associated with transfer payments to the firm in this framework. In principle, additional costs might arise if, for example, the taxes imposed to finance transfer payments create deadweight losses. Much of our analysis and qualitative findings remain largely unchanged when a marginal social cost ( $\lambda \geq 0$ ) of transfer payments is introduced (as in Laffont and Tirole, 1986, 1993). With costly transfer payments, consumer surplus in state $i$ under price $p_{i}$ and transfer payment $T_{i}$ becomes $v_{i}\left(p_{i}\right)-[1+\lambda] T_{i}$, the function $w_{i}(\bullet)$ becomes $v_{i}(\bullet)+[1+\lambda] \pi_{i}(\bullet)$, and the regulator's objective function in equation (2.2) becomes $w_{i}-[1+\lambda-\alpha] R_{i}$. The conclusions reported in Findings 1 and 2 below are essentially unchanged by the introduction of a social cost of transfer payments, provided the prices in the full-information outcome are taken to be Ramsey prices. The full-information prices are Ramsey prices, not marginal cost prices, in the setting with costly transfer payments because profit has higher social value since it permits a reduction in costly transfer payments. 


\subsection{The Setting With Unknown Variable Costs}

In the setting with unknown variable costs, the state of the environment is the firm's marginal cost of production. The firm's total cost of producing $q$ units of output in state $i$ is $C_{i}(q)=c_{i} q+F$, where $F$ is a (known) constant. ${ }^{9}$ Consequently, the firm's equilibrium rent in state $i$ in this setting is $R_{i}=\left[p_{i}-c_{i}\right] Q\left(p_{i}\right)-F+T_{i}$, where $Q(p)$ is the demand curve facing the firm. This demand curve is common knowledge in the setting with unknown variable costs. The key qualitative properties of the optimal regulatory policy in this setting are recorded in Finding 1.

Finding 1. In the setting with unknown variable costs, the solution to $[P]$ has the following properties: (i) $R_{L}>R_{H}=0$; and (ii) $p_{L}=p_{L}^{*}<p_{H}^{*}<p_{H}$.

9. This simple linear version of the unknown cost setting is analyzed for expositional ease. More generally, the state of the environment could be a parameter ( ${ }^{C}$ ), where the higher realization of ${ }^{C}$ is associated with higher total and marginal costs of production. 
Finding 1 reveals that the standard conclusions described in section 1 arise in the setting with unknown variable costs. ${ }^{10}$ In particular, as property (i) in Finding 1 reports, the firm is afforded no rent when its marginal cost is high. However, the firm commands rent from its superior ability when its marginal cost is low. Property (ii) indicates that the firm is induced to set a price that exceeds the full-information price when its marginal cost is high, and to set the full-information price when its marginal cost is low. An explanation of this pattern of rents and prices is provided in section 4, following a brief summary of the other two settings of interest.

Before reviewing these other settings, we mention briefly an alternative setting in the literature (e.g., Laffont and Tirole 1986, 1993) that is isomorphic to the setting with unknown variable costs. In this alternative setting, the regulator can observe the firm's realized marginal cost of production, but cannot observe the (fixed) cost the firm incurs to secure the realized marginal cost. The firm earns no rent under the optimal regulatory policy in this setting when it is relatively onerous for the firm to reduce its marginal cost, but enjoys positive rent otherwise (much as in property (i) of Finding l). The firm is induced to implement the cost-minimizing technology when it is relatively easy for the firm to reduce its marginal cost, but operates with an inefficiently high marginal cost otherwise. This distortion limits the rent the firm can secure by exaggerating the difficulty of reducing its marginal

10. These qualitative conclusions arise in a variety of regulatory models, including those analyzed in Baron and Myerson (1982) and Laffont and Tirole (1986). See Besanko and Sappington (1987), Caillaud et al. (1988), Laffont and Tirole (1993), Laffont (1994), Laffont and Martimort (2002), and Armstrong and Sappington (2004) for related references. 
cost. Thus, although distortions analogous to those identified in property (ii) of Finding 1 arise, marginal costs, not prices, are distorted when marginal costs are observable. The distortions in induced marginal costs limit the firm's rent directly, leaving no corresponding role for prices. Consequently, prices are optimally set equal to realized marginal costs, in order to maximize total surplus given the induced technology.

\subsection{The Setting With Unknown Variable and Fixed Costs}

The setting with unknown variable and fixed costs is analogous to the setting with unknown variable costs, with one important exception. In the setting with unknown variable and fixed costs, the firm is privately informed about both its marginal ( $c$ ) and its fixed ( $F$ ) costs of production. Furthermore, both fixed and marginal costs vary with the state of the environment. ${ }^{11}$ Most importantly, marginal and fixed costs are inversely related, so when the firm's marginal cost is low, its fixed cost is high, and when the firm's marginal cost is high, its fixed cost is low. Formally, $\Delta^{c} \equiv C_{H}-c_{L}>0$ and $\Delta^{F} \equiv F_{L}-F_{H}>0$ in the setting with unknown variable and fixed costs.

The key features of the solution to $[P]$ in this setting are summarized in Finding 2.

Finding 2. In the setting with unknown variable and fixed costs, the solution to $[P]$ has the following properties:

$$
R_{L}>R_{H}=0 \quad \text { and } \quad p_{L}=p_{L}^{*}<p_{H}^{*}<p_{H} \quad \text { if } \quad \Delta^{F}<\Delta^{c} Q\left(c_{H}\right) \text {; }
$$

11. This might be the case, for example, when feasible production technologies are known to entail a tradeoff between fixed and variable production costs, and the firm has superior information about the particular technology it employs. 
(ii) $\quad R_{H}>R_{L}=0$ and $p_{L}<p_{L}^{*}<p_{H}^{*}=p_{H} \quad$ if $\quad \Delta^{F}>\Delta^{c} Q\left(c_{L}\right)$; and

(iii) $\quad R_{H}=R_{L}=0$ and $p_{L}=p_{L}^{*}<p_{H}^{*}=p_{H} \quad$ if $\quad \Delta^{F} \in\left[\Delta^{c} Q\left(c_{H}\right), \Delta^{c} Q\left(c_{L}\right)\right]$.

Finding 2 reports that the features of the optimal regulatory policy differ significantly as the relative magnitudes of the potential variation in fixed and variable costs change. As property (i) reveals, the optimal regulatory policy in the setting with unknown variable and fixed costs has the same qualitative features as the corresponding policy in the setting with unknown variable costs whenever the potential variation in fixed costs $\left(\Delta^{F}\right)$ is sufficiently small. ${ }^{12}$ In contrast, as property (ii) indicates, different pricing distortions and rent patterns emerge when the potential variation in fixed costs is sufficiently large. Property (iii) reports that the full-information solution is feasible (and optimal) for intermediate magnitudes of $\Delta^{F} \cdot{ }^{13}$ Together, Findings 1 and 2 reveal that the qualitative features of the solution to $[P]$ can vary significantly as the nature of the firm's privileged information changes.

\subsection{The Setting With Unknown Demand}

12. Notice, in particular, that Finding 1 pertains to the special case of property (i) of Finding 2 in which $\Delta^{F}=0$.

13. Conclusions similar to those in Finding 2 are reported, for example, in Lewis and Sappington (1989), Maggi and Rodriguez-Clare (1995), and Jullien (2000). 
In contrast to both the setting with unknown variable costs and the setting with unknown variable and fixed costs, the firm's cost structure is common knowledge in the setting with unknown demand. However, the firm is privately informed about the demand function it faces. The output that consumers will purchase at price $p$ in state $i$ is $Q_{i}(p)$, where $Q_{H}(p)>Q_{L}(p)$ for all $p \geq 0$. To ensure that the regulator cannot infer consumer demand perfectly from realized consumption or costs, the regulator is presumed unable to observe either realized consumption or realized costs in this setting. Furthermore, to ensure welfare is always maximized when price and marginal cost are equated, it will be convenient to assume the firm's marginal cost curve is less steeply sloped than the inverse demand curve when the firm's marginal cost of production declines as output expands, as reflected in Assumption (A1).

Assumption (A1). $\left|C^{\prime}\left(Q_{i}(p)\right)\right|$ for $i=L, H$ when $C^{\prime \prime}(q)<0$ for all $q \geq 0$.

It will also be convenient at times to assume that demand in state $H$ exceeds demand in state $L$ by the same amount at each price, as reflected in assumption (A2). ${ }^{14}$

Assumption (A2). $Q_{H}(p)=Q_{L}(p)+k$ for all $p \geq 0$, where $k$ is a strictly positive constant.

Finding 3 summarizes the key features of the solution to $[P]$ in the setting with unknown demand. ${ }^{15}$

14. Assumption (A2) is sufficient, but not necessary, to ensure the single crossing property holds in the setting with unknown demand when marginal production costs decline with output. The role of the single crossing property is discussed further in section 4 .

15. Conclusions analogous to those in Finding 3 are reported, for example, in Riordan (1984) and Lewis and Sappington (1988). Biglaiser and Ma (1995) describe the qualitative changes that can arise when the regulated firm faces competition in the marketplace. 
Finding 3. In the setting with unknown demand, the solution to $[P]$ has the following properties:

(i) $\quad R_{L}=R_{H}=0$ and $p_{L}=p_{L}^{*} \leq p_{H}^{*}=p_{H}$ if $C^{\prime \prime}(Q) \geq 0$ for all $q \geq 0$; and

(ii) $p_{L}^{*}>p_{L}=p_{H}>p_{H}^{*}$ if $C^{\prime \prime}(q)<0$ for all $q \geq 0$, provided assumptions (A1) and (A2) hold. $^{16}$

16. The pattern of rent afforded the firm when its marginal cost declines with output varies with the likelihood of the two states. When $\phi$ is close to unity, so state $L$ is very likely, the regulator optimally chooses a regulated price close to $p_{L}^{*}$ and eliminates the firm's rent in state $L$. The firm will earn rent in state $H$ in this case because it will be able to sell additional output at a price in excess of marginal cost. In contrast, When $\phi$ is close to zero, so state $H$ is very likely, the regulator optimally chooses a regulated price close to $p_{H}^{*}$ and eliminates the firm's rent in state $H$. The firm will earn rent in state $L$ in this case because it can avoid selling some output at a price below the associated marginal cost of production. For a particular intermediate value of $\phi$, the firm may earn zero rent in both states. 
Finding 3 reports that the optimal regulatory policy varies substantially as the firm’s cost structure changes in the setting with unknown demand. If the firm produces with increasing marginal costs, the regulator can secure the full-information outcome even though the full-information price varies with the state, as property (i) reveals. In contrast, as property (ii) indicates, if the firm produces with declining marginal costs, the regulator will instruct the firm to set the same price, regardless of the realized state of the environment. Thus, in this case, in contrast to all other cases considered here, the regulator abandons any effort to induce the firm to employ its superior knowledge of the environment to increase consumer surplus. Instead, the regulator simply chooses the best single price to set, based upon her imperfect knowledge of the environment. ${ }^{17}$

\subsection{Summary}

In summary, the solution to $[P]$ exhibits very different properties depending upon the nature of the firm's private information. Prices may be set above, below, or at marginal cost, and prices may or not vary with the realized state of the environment. Furthermore, the firm may or may not be able to command rent from its private information.

\section{Toward a Unified Analysis}

The purpose of this section is to develop a unified framework within which Findings 1 through 3 can be analyzed, interpreted, and proved in a fairly simple manner.

17. Such complete pooling occurs even when the firm's private information is not binary. See Lewis and Sappington (1988). Partial pooling can arise in settings where the firm is privately informed about its fixed and variable costs when the firm's information is not binary. See, for example, Lewis and Sappington (1989), Maggi and Rodriguez-Clare (1995), and Jullien (2000). 


\subsection{Preliminary Observations}

The analysis begins with four helpful lemmas. The first lemma characterizes the difference between the firm's profit in state $H$ and its profit in state $L$ when the regulated price is $p$. Call this difference $\Delta^{\pi}(p)$.

Lemma 1. $\Delta^{\pi}(p) \equiv \pi_{H}(p)-\pi_{L}(p)$ is strictly increasing in $p$ in the setting with unknown variable costs and in the setting with unknown variable and fixed costs. $\Delta^{\pi}(p)$ is also strictly increasing in $p$ in the setting with unknown demand when assumptions (A1) and (A2) hold.

Lemma 1 states that the difference between the firm's profit in the high state and the low state increases as the regulated price increases in all three settings under consideration. This "increasing difference” property reflects the standard single crossing property that typically is imposed in adverse selection models of this sort. The property ensures the regulated firm is systematically more willing to trade a higher price for a lower transfer payment in state $H$ than in state $L .^{18}$ Consequently, as Lemma 2 reports, the regulated price will be at least as high in state $H$ as it is in state $L$ in all three settings under consideration.

Lemma 2. $p_{H} \geq p_{L}$ in any feasible solution to $[P]$, provided $\Delta^{\pi}(p)$ is strictly increasing in $p$

It is also the case that the firm's rent ( $R$ ) will be eliminated in at least one state at the solution to

18. More formally, the single crossing property holds when the firm's marginal rate of substitution of price for transfer payment varies monotonically with the underlying state. See Cooper (1984) for details. 
$[P]$. This conclusion, which is recorded in Lemma 3, follows from the fact that the incentive compatibility constraints (2.4) depend only on the difference between the firm's rent in the two states. Consequently, if $R_{L}$ and $R_{H}$ were both strictly positive, the regulator could lower both rents by the same amount without affecting the incentive compatibility constraints. Doing so would increase the regulator's equilibrium expected payoff, since rent is costly (since $\alpha<1$ ).

Lemma 3. $R_{L}=0$ and/or $R_{H}=0$ at the solution to $[P]$.

The final preliminary lemma provides a condition under which prices will be set at their fullinformation levels.

Lemma 4. Suppose the incentive compatibility constraint in state $i,(2.4)$, does not bind at the solution to $[P]$. Then $p_{j}=p_{j}^{*}$ for $j_{-} i$, where $i, j \in\{L, H\}$.

Lemma 4 reflects the following simple and well known logic. Suppose the firm were not tempted to choose the ( $\left.p_{L}, T_{L}\right)$ option in state $H$ when $p_{L}$ is set at a level other than the full-information level, $p_{L}^{*}$. Then the regulator could alter the $\left(p_{L}, T_{L}\right)$ option so as to increase her expected net payoff. She could do so by adjusting $p_{L}$ so as to increase total surplus $\left(w_{L}(\bullet)\right)$ in state $L$ and changing $T_{L}$ so as to leave the firm's rent ( $\left.R_{L}\right)$ unaltered in state $L$. The unaltered rent would ensure the firm's continued participation and selection of the $\left(p_{L}, T_{L}\right)$ option in state $L$. Furthermore, small changes in $p_{L}$ and $T_{L}$ would not affect the firm's choice of the ( $\left.p_{H}, T_{H}\right)$ option in state $H$, given its original strict preference for that option. 


\subsection{Achieving the Full-Information Outcome}

As noted in section 1, the firm commands rent from its privileged information in the "standard" regulatory problem of this sort. However, Findings 2 and 3 reveal that the firm does not secure rent from its private information in all such problems. Indeed, the regulator sometimes is able to ensure the full-information outcome. To understand when the full-information outcome is feasible, notice from inequality (2.4) that this can only be the case in the settings analyzed here when:

$$
\Delta^{\pi}\left(p_{H}^{*}\right) \geq 0 \geq \Delta^{\pi}\left(p_{L}^{*}\right) \cdot{ }^{19}
$$

Inequality (4.1) implies that the full-information outcome will not be feasible if the firm's profit is systematically higher in one state than the other. The firm's profit is always higher in state $L$ than in state $H$ at every price in the setting with unknown variable costs (since $\Delta^{\pi}(p)=$ - $\left.\Delta^{c} Q(p)<0\right)$. The firm always secures rent when its variable costs are low $\left(c_{L}\right)$ in this setting, so the regulator cannot achieve the full-information outcome.

Inequality (4.1) indicates that if the full-information outcome is to be feasible, the firm's profit functions in the two states must cross. In particular, profit must be higher in state $H$ than in state

$L$ at price $p_{H}^{*}$, but lower in state $H$ than in state $L$ at price $p_{L}^{*}$. The firm's profit functions do cross in this manner under the conditions specified in property (iii) of Finding 2 and in property (i) of Finding 3.

19. Our focus on the setting where the firm's private information is the realization of a binary random variable gives rise to the relatively simple condition specified in inequality (4.1). In more general settings, more complicated conditions typically will arise. 
In the setting with unknown variable and fixed costs, the firm's equilibrium rent at price $p$ in state $i$ is $\left[p-c_{i}\right] Q(p)-F_{i}+T_{i}$. Consequently, in this setting:

$$
\Delta^{\pi}(p)=F_{L}-F_{H}-\left[c_{H}-c_{L}\right] Q(p)=\Delta^{F}-\Delta^{c} Q(p) .
$$

Since the full-information price in state $i$ is the realized marginal cost, $c_{i}$, in this setting, expressions (4.1) and (4.2) reveal that the full-information outcome will be feasible in this setting if and only if:

$$
\Delta^{c} Q\left(c_{H}\right) \leq \Delta^{F} \leq \Delta^{c} Q\left(c_{L}\right) .
$$

Inequality (4.3) is precisely the condition specified in property (iii) of Finding 2.

Inequality (4.3) requires the difference in the firm's fixed costs ( $\left.\Delta^{F} \equiv F_{L}-F_{H}\right)$ in the two states to be intermediate between the corresponding difference in variable costs $\left(\Delta^{c} Q(\bullet)\right)$ at fullinformation prices in state $H$ and state $L$. When this condition holds, the firm has no incentive to misrepresent its private information when the regulator promises to implement the full-information price and transfer payment corresponding to the state reported by the firm (i.e., when the regulator implements $\left(p_{i}^{*}, T_{i}^{*}\right)$ whenever the firm reports the state to be state $i$, for $i=L, H$ ). Under this policy, the firm has no incentive to claim the state is $H$ when it truly is $L$. Doing so amounts to an understatement of fixed costs that exceeds the corresponding exaggeration of variable costs (since $\left.F_{L}-F_{H}>\Delta^{c} Q\left(c_{H}\right)\right)$. Similarly, the firm has no incentive to report the state is $L$ when it truly is $H$. Such a report constitutes an understatement of variable costs that exceeds the corresponding exaggeration of fixed costs (since $\left.\Delta^{c} Q\left(c_{L}\right)>F_{L}-F_{H}\right)$. Consequently, when condition (4.3) holds, this simple policy will ensure the full-information outcome in the setting with unknown 
variable and fixed costs.

As property (i) of Finding 3 reports, the regulator also can ensure the full-information outcome in the setting with unknown demand when the firm's cost function is convex. Inequality (4.1) implies this result must stem from the fact that, in each state ( $i$ ), the firm's profit at the full-information price for that state $\left(p_{i}^{*}\right)$ is higher than at the full-information price for the other state $\left(p_{j}^{*}\right)$. To verify that this is the case, let $q_{j}^{*} \equiv Q_{j}\left(p_{j}^{*}\right)$ denote the full-information output level in state $j$. Then in the setting with unknown demand:

$$
\begin{aligned}
\pi_{i}\left(p_{j}^{*}\right) & =p_{j}^{*} Q_{i}\left(p_{j}^{*}\right)-C\left(Q_{i}\left(p_{j}^{*}\right)\right) \\
& \leq p_{j}^{*} Q_{i}\left(p_{j}^{*}\right)-\left[C\left(q_{j}^{*}\right)+C^{\prime}\left(q_{j}^{*}\right)\left[Q_{i}\left(p_{j}^{*}\right)-q_{j}^{*}\right]\right] \\
& =p_{j}^{*} q_{j}^{*}-C\left(q_{j}^{*}\right)=\pi_{j}\left(p_{j}^{*}\right) .
\end{aligned}
$$

The inequality in expression (4.4) follows from the convexity of $C(\bullet)$. The second equality in expression (4.4) holds because full-information prices are marginal cost prices, so $p_{j}^{*}=C^{\prime}\left(q_{j}^{*}\right){ }^{20}$ Expression (4.4) ensures that inequality (4.1) holds in the setting with unknown demand.

Expression (4.4) indicates that when the firm's cost function is convex in the setting with unknown demand, the firm has no incentive to misrepresent its private information when the regulator promises to implement the full-information price and transfer payment for state $i,\left(p_{i}^{*}, T_{i}^{*}\right)$, whenever the firm reports the state to be state $i$ (for $i=L, H$ ). The reason for this conclusion is

20. Because Finding 3 relies upon the equality of full-information prices and marginal-cost prices, the Finding does not necessarily hold in the setting with costly transfer payments, where full-information prices are Ramsey prices. 
straightforward. Demand is higher at every price in state $H$ than in state $L$. Consequently, when marginal cost increases with output, the full-information price is higher in state $H$ than in state $L$. Furthermore, since the full-information price exceeds the marginal cost of producing all inframarginal units, the firm's revenue at the full-information price exceeds its variable cost. Consequently, abstracting from fixed costs for expositional simplicity, the firm pays a tax $\left(T^{*}<0\right)$ in the full-information outcome. The tax is the difference between the firm's revenue and variable cost in the relevant state. This tax is relatively large in state $H$, because, due to the higher demand in state $H$, the firm will sell a relatively large number of inframarginal units at a price that exceeds marginal cost.

This large tax in state $H$ is what deters the firm from exaggerating actual demand. Although an exaggeration admits a higher price $\left(p_{H}^{*}>p_{L}^{*}\right)$, it also obligates the firm to pay a higher tax. Since the tax is calculated to eliminate variable profit assuming demand is pronounced (i.e., assuming state $H$ prevails), the tax exceeds variable profit when demand is less pronounced (i.e., when state $L$ prevails). Consequently, the firm's profit in state $L$ is higher when it reports the state truthfully than when it exaggerates demand.

The firm also has no incentive to understate realized demand in the setting with unknown demand. Doing so would reduce the tax the firm must pay. However, it also would obligate the firm to satisfy the relatively large consumer demand at a low price $\left(p_{L}^{*}<p_{H}^{*}\right)$. The tax reduction is designed to offset exactly the reduction in the firm's variable profit in state $L$ caused by the reduction in price from $p_{H}^{*}$ to $p_{L}^{*}$. But this tax reduction is less than the corresponding reduction in variable profit 
in state $H$, where demand is more pronounced. ${ }^{21}$ Consequently, the firm has no incentive to misrepresent its private information, and so the full-information outcome is feasible.

\subsection{Price Distortions With Separation}

It remains to explain the optimal regulated prices when inequality (4.1) is not satisfied, so that the full-information outcome is not feasible. Consider, first, the setting with unknown variable and fixed costs, and suppose fixed costs in state $L$ exceed fixed costs in state $H$ by more than the difference between the variable costs of producing $Q\left(c_{L}\right)$ in state $H$ and in state $L$. In other words, suppose $\Delta^{F}>\Delta^{c} Q\left(c_{L}\right)$, as in property (ii) of Finding 2. In this case, since $Q(p)<$ $Q\left(c_{L}\right)$ for all $p \geq c_{L}$, the firm's profit is higher in state $H$ than in state $L$ for any price above $c_{L} \quad$ (i.e., $\Delta^{\pi}(p)>0$ for all $p \geq c_{L}$ ). Therefore, inequality (4.1) cannot hold, and so the fullinformation outcome is not feasible. Furthermore, the substantially lower fixed costs in state $H$ ensure the firm will earn rent in equilibrium in state $H$. Therefore, the firm's participation constraint (2.5) will not bind in state $H$. Consequently, Lemma 3 implies it will bind in state $L$.

When $R_{L}=0$, the incentive compatibility constraints (2.4) can be written as:

$$
\Delta^{\pi}\left(p_{L}\right) \leq R_{H} \leq \Delta^{\pi}\left(p_{H}\right) .
$$

Because rent is costly for the regulator (since $\alpha<1$ ), she will set $R_{H}$ at its smallest feasible value which, from expression (4.5), is $\Delta^{\pi}\left(p_{L}\right)$. Therefore, from expression (2.3), the regulator's objective is to maximize:

21. It can be shown that if the firm is able to ration customers with impunity, it will be indifferent between the ( $p_{L}^{*}, T_{L}^{*}$ ) and ( $p_{H}^{*}, T_{H}^{*}$ ) options in state $H$. See Lewis and Sappington (1988). 


$$
W=\phi_{w_{L}}\left(p_{L}\right)+[1-\phi]\left[w_{H}\left(p_{H}\right)-[1-\alpha] \Delta^{\pi}(p s u b L)\right] .
$$

Maximizing expression (4.6) with respect to $p_{L}$ and $p_{H}$ implies:

$$
p_{H}=p_{H}^{*} \quad \text { and } \quad p_{L}=\underset{p}{\operatorname{argmax}}\left\{w_{L}(p)-\frac{1-\phi}{\phi}[1-\alpha] \Delta \operatorname{suppi}(p)\right\}
$$

Since $\Delta^{\pi^{\prime}}(p)=-\Delta^{c} Q^{\prime}(p)>0$ in the setting with unknown variable and fixed costs, expression (4.7) implies $p_{H}=p_{H}^{*}>p_{L}^{*}>p_{L}$, as reported in property (ii) of Finding 2.

The regulator sets $p_{L}$ below $p_{L}^{*}$ when $\Delta^{F}>\Delta^{c} Q\left(c_{L}\right)$ to limit the attraction of the $\left(p_{L}, T_{L}\right)$ option to the firm in state $H$. This option is attractive to the firm because it provides a relatively large transfer payment in order to compensate the firm for its high fixed costs in state $L$. The option is rendered differentially less attractive to the firm in state $H$ than in state $L$ by increasing output above the full-information level (via reducing $p_{L}$ below $p_{L}^{*}$ ) and paying the firm $c_{L}$ per unit for the incremental output. This payment is compensatory for the firm in state $L$ when its marginal cost is $c_{L}$, but imposes marginal losses on the firm in state $H$, when its marginal cost is $c_{H}$. Therefore, although the reduction in $p_{L}$ below $p_{L}^{*}$ reduces welfare in state $L$, it limits the rent the firm commands from its privileged information in state $H$, and thereby increases the regulator's expected net payoff. The more likely is state $H$ (i.e., the greater is $1-\phi$ ) and the less highly the regulator values the firm's rent (i.e., the smaller is $\alpha$ ), the greater the deviation between $p_{L}$ and $p_{L}^{*}$ the regulator will implement to reduce the firm's rent in state $H$, as expression (4.7) reveals. 
Notice that the firm is not tempted to choose the $\left(p_{H}, T_{H}\right)$ option in state $L$ in this case. This option provides a relatively small transfer payment, since the firm’s fixed costs are relatively small in state $H$. Consequently, the ( $p_{H}, T_{H}$ ) option is not compensatory for the firm in state $L$, when its fixed costs are high. Because the firm is not tempted to choose the ( $\left.p_{H}, T_{H}\right)$ option in state $L$, the incentive compatibility constraint does not bind in state $L$ (i.e., for $i=L$ in inequality (2.4)). Therefore, from Lemma 4, $p_{H}$ is set at its full-information level, as indicated in expression (4.7).

The analysis for the setting with unknown variable costs and the setting with unknown variable and fixed costs when $\Delta^{F}<\Delta^{c} Q\left(c_{H}\right)$ is analogous. The firm will command rent from its relatively low operating costs in state $L$ in these settings, and so Lemma 3 ensures $R_{H}=0$ at the solution to $[P]$. Therefore, the incentive compatibility constraints (2.4) can be written as $-\Delta^{\pi}\left(p_{H}\right) \leq$ $R_{L} \leq-\Delta^{\pi}\left(p_{L}\right)$. Since rent is costly for the regulator, she will set $R_{L}=-\Delta^{\pi}\left(p_{H}\right)$. Therefore, from expression (2.3), her objective is to maximize:

$$
W=\phi\left[w_{L}\left(p_{L}\right)+[1-\alpha] \Delta^{\pi}\left(p_{H}\right)\right]+[1-\phi] w s u b H\left(p_{H}\right) .
$$

Maximizing (4.8) with respect to $p_{L}$ and $p_{H}$ provides:

$$
p_{L}=p_{L}^{*} \quad \text { and } \quad p_{H}=\underset{p}{\operatorname{argmax}}\left\{w_{H}(p)+\frac{\phi}{1-\phi}[1-\alpha] \Delta^{\pi}(p)\right\}
$$

Since $\Delta^{\pi}(p)$ is strictly increasing in $p$, expression (4.9) implies $p_{H}>p_{H}^{*}>p_{L}^{*}=p_{L}$, as reported in property (ii) of Finding 1 and property (i) of Finding 2. 
Because the firm is not tempted to choose the $\left(p_{L}, T_{L}\right)$ option in state $H$ in these cases, the incentive compatibility constraint in state $H$ (i.e., inequality (2.4) when $i=H$ ) does not bind. Consequently, from Lemma $4, p_{L}$ is set at its full-information level. In contrast, $p_{H}$ is raised above $p_{H}^{*}$ to limit the attraction of the $\left(p_{H}, T_{H}\right)$ option in state $L$. The price increase reduces the induced output level. The smaller output, in turn, reduces the number of units of output on which the firm can exercise its cost advantage when its marginal cost is low (in state $L$ ), and so limits the rent the firm must be promised to induce it to choose the ( $p_{L}, T_{L}$ ) option in state $L .^{22}$

22. The more likely is state $L$ (i.e., the greater is $\phi$ ) and the less highly the regulator values the firm's rent (i.e., the smaller is $\alpha$ ), the greater the deviation between $p_{H}$ and $p_{H}^{*}$ the regulator will implement to reduce the firm's rent in state $L$, as expression (4.9) reveals. In the limiting case where consumer surplus and rent are equally valuable (so $\alpha=1$ ), $p_{H}$ will be set equal to $p_{H}^{*}$, in order to maximize the sum of consumer surplus and profit $(w(\bullet)$ ) in state $H$. See Loeb and Magat (1979). 


\subsection{Pooling Prices}

Property (ii) of Finding 3 reveals that, in contrast to all other settings under consideration, the regulator may induce the firm to set the same price in both states in the setting with unknown demand. This will be the case when the firm's marginal cost declines as output increases and when assumptions (A1) and (A2) hold. This pooling arises because incentive compatible prices are fundamentally at odds with full-information prices under the specified conditions. Declining marginal costs imply that the full-information price is lower in state $H$ than in state $L$. In contrast, as Lemma 2 reports, the firm cannot be induced to set a lower price in state $H$ than in state $L$ when $\left(\Delta^{\pi}\right)^{\prime}(p)>0$, which will be the case when assumptions (A1) and (A2) hold. Therefore, when restricted to incentive compatible prices, the closest approximation to fullinformation prices the regulator can secure is a single price that does not vary with the state.

More formally, property (ii) of Finding 3 follows from the following logic. Suppose the regulator did implement distinct prices in the two states. Then $p_{H}>p_{L}$, from Lemma 2 . It is readily verified that exactly one of the incentive compatibility constraints (2.4) binds at the solution to $[P]$ in this case. $^{23}$ Suppose the constraint binds in state $H$. Then, from expression (2.4):

$$
R_{L}=R_{H}-\Delta^{\pi}\left(p_{H}\right)
$$

Furthermore, Lemma 4 implies that the full-information price is implemented in state $L$ (i.e.,

23. When $\Delta^{\pi}(p)$ is strictly increasing, both incentive compatibility constraints can bind at the solution to $[P]$ only when $p_{L}=p_{H}$. If neither incentive compatibility constraint binds, the logic that underlies Lemma 4 reveals $p_{L}=p_{L}^{*}$ and $p_{H}=p_{H}^{*}$. But $p_{H}^{*}<p_{L}^{*}$ in the present setting. Since Lemma 2 implies $p_{H} \geq p_{L}$ whenever the incentive compatibility constraints are satisfied, the initial presumption that neither constraint binds cannot hold. 
$\left.p_{L}=p_{L}^{*}\right)$. Now let $q_{L}^{*}=Q_{L}\left(p_{L}^{*}\right)$. Then, analogous to expression (4.4), notice that: 


$$
\pi_{H}\left(p_{L}^{*}\right) \quad p_{L}^{*} Q_{H}\left(p_{L}^{*}\right)-C\left(Q_{H}\left(p_{L}^{*}\right)\right)
$$




$$
>p_{L}^{*} Q_{H}\left(p_{L}^{*}\right)-\left[C\left(q_{L}^{*}\right)+C^{\prime}\left(q_{L}^{*}\right)\left[Q_{H}\left(p_{\text {Lsup }}^{*}\right)-q_{L}^{*}\right]\right]
$$




$$
p_{L}^{*} q_{L}^{*}-C\left(q_{L}^{*}\right)=\pi_{L}\left(p_{L}^{*}\right) \text {. }
$$


The inequality in expression (4.11) follows from the concavity of $C(\bullet)$. The second equality in expression (4.11) holds because $p_{L}^{*}=C^{\prime}\left(q_{L}^{*}\right)$.

Expression (4.11) implies $\Delta^{\pi}\left(p_{L}^{*}\right)>0$. Therefore, since $\Delta^{\pi}(p)$ is strictly increasing from Lemma 1 and $p_{H} \geq p_{L}$ from Lemma 2, it follows that $\Delta^{\pi}\left(p_{H}\right)>0$. Consequently, since $R_{L}=0$ or $R_{H}=0$ from Lemma 3, expression (4.10) implies:

$$
R_{L}=0 \quad \text { and } \quad R_{H}=\Delta^{\pi}\left(p_{H}\right)
$$

Expressions (2.3) and (4.12) imply the regulator's objective under the maintained assumptions is to maximize:

$$
W=\phi w_{L}\left(p_{L}\right)+[1-\phi]\left[w_{H}\left(p_{H}\right)-[1-\alpha] \Delta^{\pi}\left(p_{H}\right)\right] .
$$

$\Delta^{\pi}(p)$ is strictly increasing from Lemma 1. Furthermore, $w_{H^{\prime}}\left(p_{H}\right)<0$ when $p_{H}>p_{H}^{*}$, as postulated. Therefore, from expression (4.13), the value of the regulator's objective function would increase if $p_{H}$ were reduced. Furthermore, a small reduction in $p_{H}$, coupled with the change in $T_{H}$ required to ensure $R_{H}=\Delta^{\pi}\left(p_{H}\right)$, would not cause any of the firm's incentive compatibility or participation constraints to be violated. Consequently, the postulated divergence between $p_{H}$ and $p_{L}$ cannot constitute a solution to $[P]$. An analogous argument by contradiction reveals that $p_{H}$ cannot differ from $p_{L}$ at the solution to $[P]$ if the firm's incentive compatibility constraint binds in state $L$.

Thus, as property (ii) of Finding 3 implies, a sufficiently strong tension between incentive compatible prices and full-information prices can lead the regulator to abandon all hopes of inducing 
the firm to employ its privileged information to benefit consumers. ${ }^{24}$

\section{Conclusion}

The literature on regulatory policy design in the presence of asymmetric information includes a variety of models that admit a wide range of solutions. We have provided a simple model that admits as special cases several key models that have been analyzed in the literature. We also have offered a common approach to solving these models, and have attempted to identify and explain the key differences and similarities in the solutions to these models.

24. Complete pooling is implemented in this setting even if the regulator does not value consumer surplus more highly than rent (i.e., even if $\alpha=1$ ). Thus, pooling arises in this setting from incentive compatibility considerations, not from a desire to better limit the firm's rent. For additional analysis of the conditions under which pooling will arise in continuous adverse selection problems, see Guesnerie and Laffont (1984), Caillaud et al. (1988), and Jullien (2000). Sharkey and Sibley (1993) provide conditions under which partial pooling will arise in a discrete regulatory problem of the type analyzed here. 
Although we have analyzed several different types of discrete regulatory problems with asymmetric information, we have not analyzed all such problems. For example, we have not considered problems in which the firm's private information is multidimensional, the firm is risk averse and imperfectly informed about the environment, the interaction between the regulator and the firm is repeated, or the regulator has access to an imperfect monitor of the firm's private information. Each of these extensions of the standard regulatory model can introduce qualitative changes in optimal regulatory policy that are similar to the changes analyzed above. For instance, substantial pooling can arise in settings where the firm's private information is multidimensional, the firm is risk averse, or the regulator's intertemporal commitment powers are limited. Furthermore, output in excess of full-information levels may be induced when the firm's private information is multidimensional or when the regulator's intertemporal commitment powers are limited. In addition, the regulator may be able to ensure the full-information outcome when she has access to an imperfect monitor of the firm's private information. ${ }^{25}$ A complete synthesis of this broader array of problems awaits further research. ${ }^{26}$

25. See Armstrong and Sappington (2004) and the references cited therein for further analysis of these conclusions.

26. Of course, a broader synthesis that incorporates non-binary models would be useful. A synthesis that includes both adverse selection (hidden information) and moral hazard (hidden action) models also would be valuable. Armstrong and Sappington (2004) provide a simple review and analysis of regulatory moral hazard models in which a regulator seeks to induce a firm to undertake unobservable investment (e.g., effort) to reduce its (observable) operating costs. 


\section{Appendix}

\section{Proof of Lemma 1.}

Since $\pi_{i}(p)=\left[p-c_{i}\right] Q(p)-F_{i}+T_{i}$ in the setting with unknown variable costs and in the setting with unknown variable and fixed costs, $\Delta^{\pi^{\prime}}(p)=-\left[c_{H}-c_{L}\right] Q^{\prime}(p)>0$ in these settings. In the setting with unknown demand: 
$\Delta^{\pi^{\prime}}(p) \quad\left[p-C^{\prime}\left(Q_{H}(p)\right)\right] Q_{H^{\prime}}(p)+Q_{H}(p)-\left[p-C^{\prime}\left(Q_{L}(p)\right)\right] Q_{L^{\prime}}(p)-Q_{L}(p)$ (A) 


$$
\left[C^{\prime}\left(Q_{L}(p)\right)-C^{\prime}\left(Q_{H}(p)\right)\right] Q_{H^{\prime}}(p)+Q_{H}(p)-Q_{L}(p) \text {. }
$$


The equality in expression (A2) follows from assumption (A2). Since $Q_{H}(p)>Q_{L}(p)$ and $Q_{H^{\prime}}(p)<0$ for all $p \geq 0$, both terms in expression (A2) are non-negative when $C^{\prime \prime}(q) \geq 0$ for all $q \geq 0$.

Furthermore, assumption (A1) implies that when $C^{\prime \prime}(q)<0$ for all $q>0$ :

$$
\begin{aligned}
C^{\prime}\left(Q_{L}(p)\right)-C^{\prime}\left(Q_{H}(p)\right)=\int_{Q_{L}(p)}^{Q_{H}(p)}\left|C^{\prime \prime}(q)\right| d q<\left|C^{\prime \prime}\left(Q_{L}(p)\right)\right|\left[Q_{H}(p)-Q_{L}(p)\right] \\
\quad<\left[Q_{H}(p)-Q_{L}(p)\right] /\left|Q_{H^{\prime}}(p)\right| .
\end{aligned}
$$

The inequality in expression (A3) holds because $C^{\prime \prime}(q)<0$. The inequality in expression (A4) follows from assumption (A1), using the fact that $Q_{L^{\prime}}(p)=Q_{H^{\prime}}(p)$, from assumption (A2). The inequality in (A4) ensures the terms in expression (A2) are strictly positive.

\section{Proof of Lemma 2.}

Inequality (2.4) ensures

$$
R_{L} \geq R_{H}-\Delta^{\pi}\left(p_{H}\right) \quad \text { and } \quad R_{H} \geq R_{L}+\Delta^{\pi}\left(p_{L}\right)
$$

The two inequalities in (A5) imply:

$$
\Delta^{\pi}\left(p_{H}\right) \geq \Delta^{\pi}\left(p_{L}\right)
$$

Inequality (A6) implies $p_{H} \geq p_{L}$, since $\Delta^{\pi}(p)$ is strictly increasing, by Lemma 1 .

\section{References}


Armstrong, M. and D. Sappington. 2004. "Recent Developments in the Theory of Regulation.” To appear in The Handbook of Industrial Organization, edited by M. Armstrong and R. Porter. Amsterdam: Elsevier Science Publishers.

Baron, D. and R. Myerson. 1982. "Regulating a Monopolist with Unknown Costs.” Econometrica 50(4): 911-930.

Besanko, D. and D. Sappington. 1987. Designing Regulatory Policy With Limited Information. London: Harwood Academic Publishers.

Biglaiser, G. and C. Ma. 1995. "Regulating a Dominant Firm: Unknown Demand and Industry Structure.” Rand Journal of Economics 26(1): 1-19.

Caillaud, B., R. Guesnerie, P. Rey, and J. Tirole. 1988. "Government Intervention in Production and Incentives Theory: A Review of Recent Contributions.” Rand Journal of Economics 19(1): 126.

Cooper, R. 1984. "On Allocative Distortions in Problems of Self-Selection.” Rand Journal of Economics 15(4): 568-577.

Crew, M. and P. Kleindorfer. 1996. "Incentive Regulation in the United Kingdom and the United States: Some Lessons.” Journal of Regulatory Economics 9(3): 211-225.

Guesnerie, R. and J. Laffont. 1984. "A Complete Solution to a Class of Principal-Agent Problems with an Application to the Control of a Self-Managed Firm.” Journal of Public Economics 25(2): 329-369.

Jullien, B. 2000. "Participation Constraints in Adverse Selection Models.” Journal of Economic Theory 93(1): 1-47.

Jullien, B., B. Salanié, and F. Salanié. 2003. "Screening Risk-Averse Agents Under Moral Hazard: Single-Crossing and the CARA Case.” Université de Toulouse working paper.

Laffont, J. 1994. “The New Economics of Regulation Ten Years After.” Econometrica 62(3): 507538.

Laffont, J., and D. Martimort. 2002. The Theory of Incentives: The Principal-Agent Model. Princeton, NJ: Princeton University Press.

Laffont, J., and J. Tirole. 1986. “Using Cost Observation to Regulate Firms.” Journal of Political Economy 94(3): 614-641.

Laffont, J., and J. Tirole. 1993. A Theory of Incentives in Procurement and Regulation. Cambridge, MA: MIT Press. 
Lewis, T., and D. Sappington. 1998. “Regulating a Monopolist with Unknown Demand.” American Economic Review 78(5): 986-998.

Lewis, T., and D. Sappington. 1989. “Countervailing Incentives in Agency Problems.” Journal of Economic Theory 49(2): 294-313.

Loeb, M. and W. Magat. 1979. “A Decentralized Method for Utility Regulation.” Journal of Law and Economics 22(2): 399-401.

Maggi, G., and A. Rodriguez-Clare. 1995. “On Countervailing Incentives.” Journal of Economic Theory 66(1): 238-263.

Riordan, M. 1984. “On Delegating Price Authority to a Regulated Firm.” Rand Journal of Economics 15(1): 108-115.

Sharkey, W., and D. Sibley. 1993. “Optimal Non-Linear Pricing With Regulatory Preference Over Customer Type.” Journal of Public Economics 50(2): 197-229.

Vogelsang, I. 2002. "Incentive Regulation and Competition in Public Utility Markets: A 20-Year Perspective." Journal of Regulatory Economics 22(1): 5-28. 